\title{
Factors affecting quality of life in children and adolescents with thalassemia in Iraqi Kurdistan
}

Najbeer A. Mikael, MBChB, Nasir AS Al-Allawi, PhD, FRCPath.

\section{ABSTRACT}

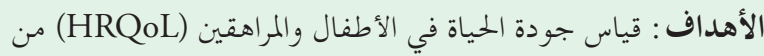

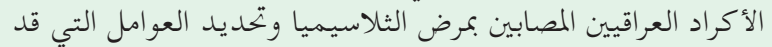

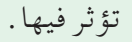

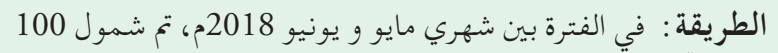

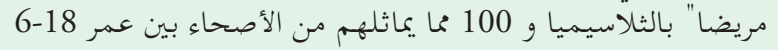

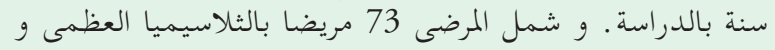

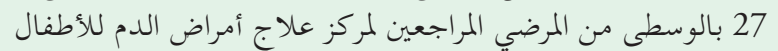

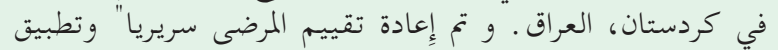

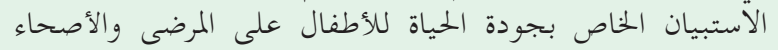

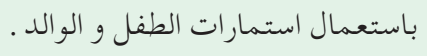

النتائج: كان معدل جودة الحياة في مرضِى الثلاسيميا أقل بشكل

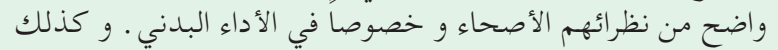

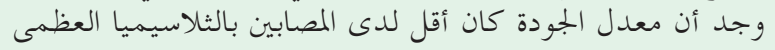

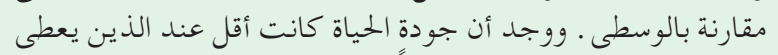

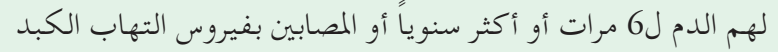

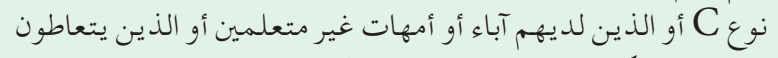

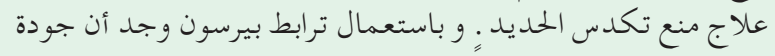

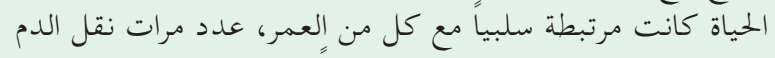

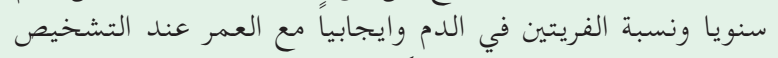

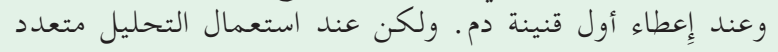

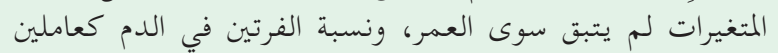
مهمين من الناحية الاحصائية.

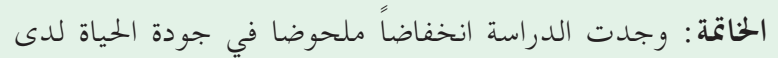

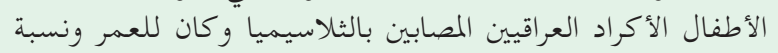

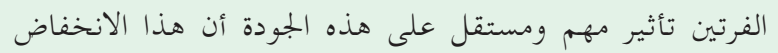

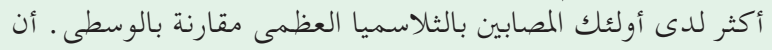

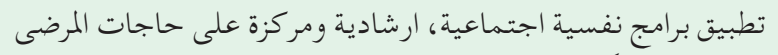

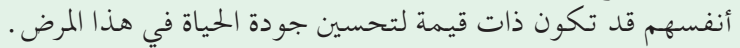

Objectives: To assess the health related quality of life (HRQoL) in Iraqi Kurd children and adolescents with thalassemia, and identify the factors that affect it.
Methods: In the period between May and June 2018, 100 thalassemic patients and 100 healthy subjects between the ages of 6-18 years were enrolled. The patients included 73 with thalassemia major (TM) and 27 with intermedia (TI). Patients were clinically re-evaluated, and the pediatric quality of life inventory (PedsQL) 4.0 was administered by both child and parent reports.

Results: The mean HRQoL score of thalassemic patients was significantly lower than that of healthy subjects, with lowest scores in physical functioning. Furthermore, the mean HRQoL of TM was significantly lower than that of TI subgroup. Significantly lower mean HRQoL scores were seen in those taking $\geq 6$ transfusions/year, with hepatitis $\mathrm{C}$ infection, with illiterate parents, and those on oral iron chelation. Pearson correlation revealed that HRQoL was negatively associated with age, frequency of transfusions, and serum ferritin, but positively correlated with age at starting transfusion and age at diagnosis. Only age and serum ferritin remained significant by multivariate analysis.

Conclusion: This study shows that among Iraqi Kurds with thalassemia, the disease has a significant negative impact on quality of life, with age and serum ferritin being identified as independent predictors. Psychosocial, educational, and patient-centered management programs may be needed to improve HRQoL in this disease.

Saudi Med J 2018; Vol. 39 (8): 799-807

doi:10.15537/smj.2018.8.23315

From the Department of Hematology (Mikael), Azadi Teaching Hospital, and from the Department of Pathology (Al-Allawi), College of Medicine, University of Duhok, Duhok, Iraq.

Received 15th June 2018. Accepted 30th July 2018.

Address correspondence and reprint request to: Prof. Nasir Al-Allawi, Department of Pathology, College of Medicine, Duhok, Iraq. E-mail:nallawi@yahoo.com

ORCID ID: orcid.org/0000-0002-3408-6602 
$\mathrm{T}$ halassemia is a group of inherited blood disorders caused by defects in one or more genes responsible for producing the globin chains of hemoglobin. They are broadly classified according to the affected globin chain, into alpha $(\alpha)$ or beta $(\beta)$-thalassemias. ${ }^{1}$ Beta thalassemia encompasses a wide range of clinical phenotypes ranging from the severe, transfusion dependent thalassemia major, to the almost asymptomatic thalassemia minor, with the phenotype thalassemia intermedia being intermediate between these 2 extremes. ${ }^{2}$ Among the phenotypes associated with alpha thalassemia, the only clinically significant is hemoglobin $\mathrm{H}$ disease, which also presents as thalassemia intermedia. ${ }^{3}$

Beta thalassemia major is a serious life-limiting disease requiring regular monthly blood transfusion, and is associated with a variety of complications, necessitating regular clinical monitoring and hospital visits/admissions. Thalassemia intermedia patients, on the other hand, tend to be diagnosed later in life, are much less likely to be transfused, and live longer but with increased burden of additional complications. ${ }^{4}$ In both these symptomatic forms of thalassemia, the disease will impact several aspects of patients' lives, and with improved diagnostic monitoring, early and prompt identification and therapy of complications and the use of adequate chelation, patients' survival improved and the need is shifting from prolonging life per se to ensuring that patients enjoy a better quality of life $(\mathrm{QoL})$.

Health Related Quality of Life (HRQoL) is a multidimensional construct which attempts to assess the individual's own perceptions of the impact of the illness and/or its management on physical, and psychosocial functioning. ${ }^{5,6}$ Several investigators have devised questionnaires to assess HRQoL in children with chronic diseases, but the need to create a consensus instrument mounted over the years. In 2001, Dr. James Varni introduced the PedsQL 4.0 generic core scale to measure the essential core functioning for pediatric HRQoL in 4 main domains including physical, emotional, school and social functioning. PedsQL 4.0 questionnaire gained wide acceptance as a tool in pediatric healthy and diseased populations, because of its reliability, validity, and practicality. ${ }^{7-10}$

While the numerous HRQoL studies in developed countries have been utilized effectively to improve patients' care, such studies and their practical application

Disclosure. Authors have no conflict of interests, and the work was not supported or funded by any drug company. are limited in developing countries, including Iraq. ${ }^{11,12}$ Thus, the current study was initiated aiming at assessing the HRQoL in symptomatic thalassemia patients in a main thalassemia center in Iraqi Kurdistan, and determining its main clinical and demographic correlations.

Methods. This case-control study was conducted among children and adolescents with thalassemia major and intermedia between the age of 6-18 years who received treatment at Jin Pediatric Oncology and Blood Diseases Center, Duhok, Iraq over a 5 week period (during May and June 2018). One hundred patients participated in the study including 73 thalassemia major, and 27 thalassemia intermedia patients. The diagnoses of all enrolled patients were documented by clinical and hematological assessment with/or without molecular studies. The second sample was a convenience sample of 100 healthy children recruited from 4 schools serving the same locality. Patients with severe cognitive impairment or who had bone marrow transplants were excluded.

The HRQoL assessment was performed using the Pediatric Quality of Life Inventory ${ }^{\mathrm{TM}}\left(\right.$ PedsQL $\mathrm{L}^{\mathrm{TM}}$ ) 4.0 Generic Core Scale, after the completion of the relevant user agreement form. Since no Kurdish version of PedsQL was available at the time, and to ensure that the native language of the region was used, the authors contacted the Mapi Institute (Paris, France) and completed a translation agreement form to create a Kurdish version. The steps required by the Mapi Institute for the process of translation were followed and a final version was created and linguistically validated and approved by the copyright owner Dr James Varni. Pediatric Quality of Life Generic Core scale includes a total of 23 items, which is applicable to pediatric healthy, acutely and chronically diseased populations. ${ }^{8}$ Item responses are measured on a 5-point rating scale ranging from 0 (never a problem) to 4 (almost always a problem). The 23 items were distributed on 4 domains, one is physical functioning (8 items), while the other 3 are psychosocial domains including emotional, social, and school functioning (5 items each). The outcome would be a total score in each domain and mean overall score. Each scale has a reverse score ranging from 0-100, with higher scores indicating the better health-related life quality. ${ }^{7}$ The questionnaire is self-administered by both the child and parent (child self-report and parent proxy report), except for children $\leq 7$ years or children/ adults who were illiterate. In the latter situation, the questionnaire was administered by one of the authors as an interviewer. Based on the current study, the 
Kurdish version was found to be feasible, since missing item responses for both child and parent proxy reports were minimal (1.15\% and $1 \%$ respectively), and those with highest scores (ceiling effect) ranged from $1 \%$ in physical functioning to $13.5 \%$ in social functioning for child report, while the respective values for parent proxy reports ranged from $2 \%$ to $12 \%$. Those with lowest scores (floor effect) ranged from $0 \%$ in all domains in child and parent proxy reports, except for physical functioning which was $0.5 \%$ in both reports. Furthermore, the Cronbach's alpha reliability for internal consistency of the Kurdish version in the current study was found to be 0.88 and 0.87 for overall score in child and parent proxy reports respectively, while the respective values for physical functioning were 0.85 and 0.86 , and 0.80 and 0.78 for psychosocial functioning. This approaches the values reported by Varni et al in the original US English version..$^{7-10}$

All patients had their records reviewed, and demographic data as well as basic clinical findings were documented. Several parameters were particularly scrutinized, including age at diagnosis, time to first transfusion (from birth to first transfusion or if not transfused, from birth to time of enrollment), number of transfusions per year, serum ferritin, type and age of starting chelation therapy, hepatitis C RNA testing results, and parents Literacy.
The study was approved by the Ethics Committee at the Kurdistan Board of Medical Specialization, Iraqi Kurdistan, and was consistent with the ethics standards as set by 1964 Helsinki declaration and its later amendments. Informed consent was obtained from the guardians of all enrolled children.

Statistical analysis. Data were analyzed by an SPSS software (release 20, SPSS inc., Chicago, IL, USA). Health Related Quality of Life score for each domain and mean overall scores were presented in terms of means and standard deviations. Pearson's correlation, Chi-square, and independent-sample t-test were used wherever applicable. For parameters found to be significantly associated with HRQoL by univariate analysis, multivariate linear regression was used, after confirming normal distribution by Shapiro Wilk test. A $p<0.05$ was considered significant.

Results. The current study included a total of 100 symptomatic thalassemia patients, who had a mean age of 12.3 years (SD 3.68) and included 49 males and 51 females (M:F ratio 1:1.04). In addition, a total of 100 age and gender matched controls who had a mean age of 11.8 years (SD 3.78) and included 49 males and 51 females were recruited. There were no significant differences between age of patients and controls $(p=0.274)$.

Table 1 - Characteristics of 100 patients with thalassemia major and thalassemia intermedia.

\begin{tabular}{|c|c|c|c|c|}
\hline Characteristics & $\begin{array}{c}\text { Total } \\
(\mathbf{n}=100)\end{array}$ & $\begin{array}{l}\text { Thalassemia major } \\
\qquad(\mathrm{n}=73)\end{array}$ & $\begin{array}{c}\text { Thalassemia } \\
\text { intermedia } \\
(\mathbf{n}=27)\end{array}$ & $P$-value* \\
\hline Age (years) $($ mean $\pm S D)$ & $12.3 \pm 3.68$ & $12.3 \pm 3.58$ & $12.3 \pm 4.02$ & 0.996 \\
\hline \multicolumn{5}{|l|}{ Gender (n) } \\
\hline Males & 49 & 35 & 14 & \multirow[t]{2}{*}{0.729} \\
\hline Females & 51 & 38 & 13 & \\
\hline Age at diagnosis (years) $($ mean $\pm S D)$ & $1.3 \pm 1.84$ & $0.8 \pm 0.69$ & $2.7 \pm 3.0$ & 0.003 \\
\hline Age at first transfusion (years) $($ mean $\pm S D)$ & $3.0 \pm 4.22$ & $1.2 \pm 1.93$ & $7.8 \pm 4.97$ & $<0.0005$ \\
\hline Age at first chelation (years) $($ mean $\pm S D)$ & $6.7 \pm 3.73$ & $6.4 \pm 3.44$ & $8.6 \pm 5.41$ & 0.284 \\
\hline Pre-transfusion $\mathrm{Hb}(\mathrm{g} / \mathrm{dl})(\operatorname{mean} \pm \mathrm{SD})$ & $8.6 \pm 1.25$ & $8.5 \pm 1.11$ & $8.8 \pm 1.56$ & 0.326 \\
\hline Serum ferritin level $(\mathrm{ng} / \mathrm{ml})(\mathrm{mean} \pm \mathrm{SD})$ & $2915 \pm 2300$ & $3704 \pm 2143$ & $783 \pm 981$ & $<0.0005$ \\
\hline \multicolumn{5}{|l|}{ Iron chelation (oral) (n) } \\
\hline Yes & 81 & 72 & 9 & \multirow[t]{2}{*}{$<0.0005$} \\
\hline No & 19 & 1 & 18 & \\
\hline \multicolumn{5}{|l|}{ Hepatitis C infection ( $n$ ) } \\
\hline Positive & 17 & 17 & 0 & \multirow[t]{2}{*}{0.014} \\
\hline Negative & 83 & 56 & 27 & \\
\hline \multicolumn{5}{|l|}{ Parents education (no. father/no. mother) } \\
\hline Illiterate & $56 / 47$ & $48 / 38$ & $8 / 9$ & \multirow[t]{2}{*}{$0.001 / 0.095$} \\
\hline Literate & $44 / 53$ & $25 / 35$ & $19 / 18$ & \\
\hline \multicolumn{5}{|l|}{ Frequency of blood transfusion (n) } \\
\hline$<6$ times/year & 18 & 0 & 18 & \multirow[t]{2}{*}{$<0.0005$} \\
\hline$\geq 6$ times/year & 82 & 73 & 9 & \\
\hline
\end{tabular}


Table 1 outlines the main characteristics of the patients' group, which included 73 patients with thalassemia major and 27 with intermedia (including 22 $\beta$-thalassemia intermedia and 5 hemoglobin $\mathrm{H}$ disease). Based on the child's report, the mean HRQoL in our thalassemic patients (overall) was found to be $64.63 \%$ (SD 9.14). The lowest scores were encountered in the physical functioning domain at $61.77 \%$ (SD 13.37), while the highest scores were seen in social functioning at $68.55 \%$ (SD 10.37). These scores were significantly lower than those seen among healthy controls, in mean as well as the 4 individual domains. However, and within the patients' group, there were no significant differences between males and females, neither in the mean nor in any of its domains (Table 2). The parent proxy reports, showed a lower mean HRQoL scores than their child's reports in all domains and in the mean scores, with highly significant differences in physical and emotional functioning and mean scores (Table 2). However, the parent proxy and child's scores were significantly correlated in all domains and in the mean scores (all at $p<0.0005$ ) (Figure 1).

When the HRQoL of those with thalassemia major and intermedia were compared, it was found that mean scores for both child and parent proxy reports were significantly lower in thalassemia major, which was due to significant reductions of HRQoL in all domains, except for school functioning (Table 2).

A search for other predictors of child's and parent

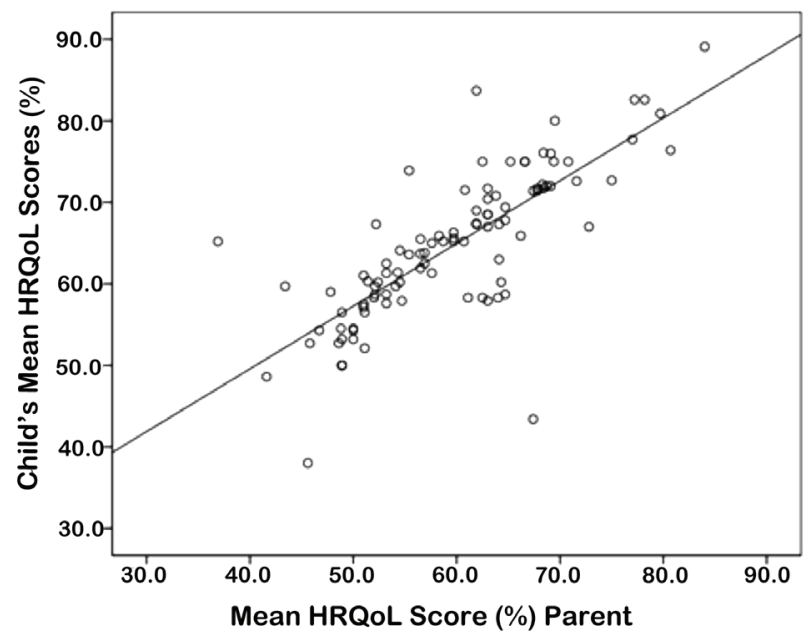

Figure 1 - Scatter plot showing the correlation between mean Health Related Quality of Life (HRQoL) scores for children and their respective parents (Pearson correlation 0.779; $p<0.0005$ ).

Table 2 - Health Related Quality of Life (HRQoL) scores in child and parent reports, in both patients and controls and comparisons within the patients' group.

\begin{tabular}{|c|c|c|c|c|c|}
\hline \multirow[t]{2}{*}{ Category } & \multicolumn{5}{|c|}{ HRQoL Scores (\%) } \\
\hline & Physical & Emotional & Social & School & Mean \\
\hline \multicolumn{6}{|l|}{ Controls (mean $\pm S D)$} \\
\hline Child & $79.14 \pm 11.41$ & $74.23 \pm 17.22$ & $87.23 \pm 12.66$ & $80.47 \pm 15.80$ & $80.38 \pm 9.92$ \\
\hline Parent proxy & $74.74 \pm 12.34$ & $68.34 \pm 15.80$ & $83.9 \pm 13.17$ & $74.37 \pm 16.65$ & $75.52 \pm 9.99$ \\
\hline$P$-value & 0.01 & 0.013 & 0.07 & 0.01 & 0.001 \\
\hline \multicolumn{6}{|l|}{ Patients (mean $\pm S D)$} \\
\hline Child* & $61.77 \pm 13.37$ & $65.79 \pm 11.54$ & $68.55 \pm 10.37$ & $63.20 \pm 12.65$ & $64.63 \pm 9.14$ \\
\hline Parent proxy* & $55.59 \pm 12.94$ & $58.49 \pm 11.66$ & $66.82 \pm 10.31$ & $59.27 \pm 12.24$ & $59.58 \pm 9.25$ \\
\hline$P$-value & 0.001 & $<0.0005$ & 0.239 & 0.055 & $<0.0005$ \\
\hline \multicolumn{6}{|c|}{ Comparisons within the patients' group } \\
\hline \multicolumn{6}{|c|}{ Child report (mean $\pm S D)$} \\
\hline Males & $61.64 \pm 13.31$ & $66.73 \pm 10.58$ & $69.95 \pm 10.63$ & $61.46 \pm 13.57$ & $64.64 \pm 9.40$ \\
\hline Females & $61.89 \pm 13.55$ & $64.88 \pm 12.42$ & $67.21 \pm 10.03$ & $65.29 \pm 11.28$ & $64.63 \pm 8.97$ \\
\hline P-value & 0.926 & 0.423 & 0.188 & 0.193 & 0.994 \\
\hline Thalassemia major & $58.56 \pm 12.17$ & $64.16 \pm 11.75$ & $67.12 \pm 9.45$ & $63.09 \pm 12.53$ & $62.80 \pm 8.25$ \\
\hline Thalassemia intermedia & $70.44 \pm 12.78$ & $70.19 \pm 9.85$ & $72.41 \pm 11.88$ & $63.50 \pm 13.29$ & $69.61 \pm 9.72$ \\
\hline$P$-value & $<0.0005$ & 0.02 & 0.023 & 0.902 & 0.001 \\
\hline \multicolumn{6}{|c|}{ Parent proxy report (mean $\pm S D)$} \\
\hline Males & $54.86 \pm 13.86$ & $57.17 \pm 11.39$ & $67.09 \pm 10.92$ & $58.54 \pm 12.26$ & $58.63 \pm 9.80$ \\
\hline Females & $56.29 \pm 12.08$ & $59.75 \pm 11.88$ & $66.57 \pm 9.78$ & $60.14 \pm 12.34$ & $60.49 \pm 8.69$ \\
\hline$P$-value & 0.583 & 0.269 & 0.801 & 0.574 & 0.319 \\
\hline Thalassemia major & $52.17 \pm 11.46$ & $56.69 \pm 11.32$ & $65.11 \pm 9.16$ & $58.36 \pm 10.93$ & $57.43 \pm 7.94$ \\
\hline Thalassemia intermedia & $64.82 \pm 12.35$ & $63.33 \pm 11.35$ & $71.43 \pm 11.92$ & $61.75 \pm 15.33$ & $65.39 \pm 10.16$ \\
\hline$P$-value & $<0.0005$ & 0.011 & 0.006 & 0.292 & $<0.0005$ \\
\hline
\end{tabular}


Table 3 - Comparison of Related Quality of Life (HRQoL) scores (child's report) in association with some disease related parameters in the thalassemic patients.

\begin{tabular}{|c|c|c|c|c|c|}
\hline \multirow[t]{2}{*}{ Parameter } & \multicolumn{5}{|c|}{ Child's HRQoL (\%) Scores $($ Mean $\pm S D)$} \\
\hline & Physical & Emotional & Social & School & Mean \\
\hline \multicolumn{6}{|c|}{ Parent's education } \\
\hline \multicolumn{6}{|l|}{ Father } \\
\hline Literate & $65.74 \pm 12.82$ & $66.36 \pm 13.09$ & $71.47 \pm 10.32$ & $65.76 \pm 10.69$ & $67.13 \pm 8.51$ \\
\hline Illiterate & $58.65 \pm 13.07$ & $65.33 \pm 10.25$ & $66.25 \pm 9.91$ & $61.19 \pm 13.78$ & $62.67 \pm 9.21$ \\
\hline$P$-value & 0.008 & 0.660 & 0.012 & 0.121 & 0.015 \\
\hline \multicolumn{6}{|l|}{ Mother } \\
\hline Literate & $65.32 \pm 12.92$ & $66.04 \pm 11.86$ & $71.04 \pm 9.68$ & $65.49 \pm 10.48$ & $66.79 \pm 8.41$ \\
\hline Illiterate & $57.76 \pm 12.84$ & $65.50 \pm 11.28$ & $65.74 \pm 10.52$ & $60.44 \pm 14.53$ & $62.20 \pm 9.40$ \\
\hline$P$-value & 0.004 & 0.819 & 0.01 & 0.085 & 0.012 \\
\hline \multicolumn{6}{|c|}{ Pre-transfusion hemoglobin } \\
\hline$<9.0 \mathrm{~g} / \mathrm{dl}$ & $62.10 \pm 13.04$ & $66.88 \pm 10.44$ & $68.26 \pm 9.84$ & $63.08 \pm 12.99$ & $65.04 \pm 9.24$ \\
\hline$\geq 9.0 \mathrm{~g} / \mathrm{dl}$ & $61.03 \pm 14.26$ & $63.35 \pm 13.54$ & $69.19 \pm 11.63$ & $63.48 \pm 12.10$ & $63.73 \pm 8.99$ \\
\hline$P$-value & 0.713 & 0.157 & 0.680 & 0.900 & 0.509 \\
\hline \multicolumn{6}{|c|}{ Transfusion/years; $n$} \\
\hline$<6$ & $71.79 \pm 0.12 .89$ & $71.67 \pm 10.57$ & $74.17 \pm 12.63$ & $64.62 \pm 12.82$ & $71.16 \pm 9.49$ \\
\hline$\geq 6$ & $59.57 \pm 12.51$ & $64.50 \pm 11.40$ & $67.32 \pm 9.46$ & $62.90 \pm 12.69$ & $63.20 \pm 8.47$ \\
\hline$P$-value & $<0.0005$ & 0.016 & 0.010 & 0.660 & 0.001 \\
\hline \multicolumn{6}{|c|}{ Ferritin $(n g / m l)$} \\
\hline$<2500$ & $67.93 \pm 11.46$ & $68.91 \pm 11.15$ & $71.85 \pm 11.71$ & $66.72 \pm 11.89$ & $69.06 \pm 8.41$ \\
\hline$\geq 2500$ & $56.52 \pm 12.70$ & $63.12 \pm 11.28$ & $65.74 \pm 8.19$ & $60.58 \pm 12.69$ & $60.86 \pm 8.03$ \\
\hline$P$-value & $<0.0005$ & 0.012 & 0.004 & 0.037 & $<0.0005$ \\
\hline \multicolumn{6}{|l|}{ Chelation } \\
\hline Yes & $59.25 \pm 12.46$ & $64.61 \pm 11.50$ & $67.59 \pm 9.68$ & $62.67 \pm 12.64$ & $63.10 \pm 8.48$ \\
\hline No & $72.50 \pm 11.95$ & $70.79 \pm 10.58$ & $72.63 \pm 12.40$ & $65.33 \pm 12.88$ & $71.19 \pm 9.17$ \\
\hline$P$-value & $<0.0005$ & 0.035 & 0.056 & 0.469 & $<0.0005$ \\
\hline \multicolumn{6}{|c|}{ Hepatitis C infection } \\
\hline Yes & $56.24 \pm 8.30$ & $62.06 \pm 8.11$ & $66.62 \pm 6.67$ & $60.0 \pm 6.32$ & $60.64 \pm 5.26$ \\
\hline No & $62.90 \pm 13.95$ & $66.55 \pm 12.02$ & $68.95 \pm 10.97$ & $63.75 \pm 13.39$ & $65.45 \pm 9.57$ \\
\hline$P$-value & 0.012 & 0.144 & 0.402 & 0.150 & 0.006 \\
\hline
\end{tabular}

proxy HRQoL scores, revealed that the mean scores were significantly lower among those with 6 or more transfused units/year, had serum ferritin in excess of $2500 \mathrm{ng} / \mathrm{ml}$, were on chelation therapy, had illiterate father/mother, or had detectable hepatitis C RNA (Tables 3 \& 4).

Using Pearson's correlation, a negative correlation was observed with age, number of transfusions/year, and serum ferritin and a positive one with the age of starting transfusion and age at diagnosis, in relation to child's mean QoL scores (Figure 2). Comparable significant correlation were similarly noted with parent proxy HRQoL. While there were no significant correlations in neither the child's nor parent proxy mean HRQoL with the age at starting chelation $(p=0.105 / p=0.185)$, or pre-transfusion hemoglobin concentration $(p=0.853$ / $p=0.416$ ).

Multiple linear regression including predictors found significant by univariate analysis, revealed that only age, and serum ferritin remained significantly associated with mean HRQoL ( $p=0.015$, and $p=0.003$ ), while transfusion frequency was just barely significant $(p=0.05)$ for child's report. Age and ferritin remained significant for the parent proxy report $(p=0.003$ and $p=0.027$ ) (Table 5).

Discussion. Measuring the HRQoL in patients with hemoglobinopathies is a unique way to determine the patient's perspective of their disease and its impact on their lives. It is important to guide management decisions aimed not only at prolonging life, but also ensuring that such decisions will improve the QoL of these patients.

The current study showed that thalassemic adolescents and children had much lower mean HRQoL scores than their healthy counterparts, which was encountered in all 4 domains assessed. The latter is consistent with the deleterious effects of the disease on different life aspects whether physical, emotional, social or educational. The child self-reported mean scores in the current study were similar to those reported from some other Middle Eastern countries, including Jordan, Egypt and Saudi Arabia where mean scores ranged from 59.1-63.7\%. ${ }^{13-15}$ Though studies from other Asian countries like Pakistan, Thailand and Malaysia reported higher HRQoL mean scores (68.5- 
Table 4 - Comparison of Health Related Quality of Life (HRQoL) (parent proxy's report) in association with some disease related parameters in the thalassemic patients.

\begin{tabular}{|c|c|c|c|c|c|}
\hline \multirow[t]{2}{*}{ Parameter } & \multicolumn{5}{|c|}{ Parent Proxy HRQoL (\%) Scores $($ Mean \pm SD) } \\
\hline & Physical & Emotional & Social & School & Mean \\
\hline \multicolumn{6}{|c|}{ Parent's education } \\
\hline \multicolumn{6}{|l|}{ Father } \\
\hline Literate & $58.73 \pm 11.70$ & $59.26 \pm 13.19$ & $68.98 \pm 10.11$ & $63.48 \pm 11.35$ & $62.15 \pm 9.26$ \\
\hline Illiterate & $53.12 \pm 13.43$ & $57.88 \pm 10.37$ & $65.13 \pm 10.231$ & $55.95 \pm 12.01$ & $57.56 \pm 8.80$ \\
\hline$P$-value & 0.03 & 0.559 & 0.064 & 0.007 & 0.013 \\
\hline \multicolumn{6}{|l|}{ Mother } \\
\hline Literate & $57.90 \pm 12.51$ & $58.58 \pm 12.41$ & $68.53 \pm 10.57$ & $62.32 \pm 11.62$ & $61.34 \pm 9.38$ \\
\hline Illiterate & $52.98 \pm 13.05$ & $58.38 \pm 10.88$ & $64.89 \pm 9.75$ & $55.59 \pm 12.11$ & $57.60 \pm 8.78$ \\
\hline$P$-value & 0.057 & 0.929 & 0.078 & 0.017 & 0.043 \\
\hline \multicolumn{6}{|c|}{ Pre-transfusion hemoglobin } \\
\hline$<9.0 \mathrm{~g} / \mathrm{dl}$ & $56.02 \pm 12.91$ & $59.11 \pm 11.45$ & $67.01 \pm 9.71$ & $58.27 \pm 11.92$ & $59.76 \pm 9.28$ \\
\hline$\geq 9.0 \mathrm{~g} / \mathrm{dl}$ & $54.62 \pm 13.16$ & $57.10 \pm 12.16$ & $66.41 \pm 11.67$ & $61.52 \pm 12.92$ & $59.16 \pm 9.32$ \\
\hline$P$-value & 0.617 & 0.427 & 0.790 & 0.292 & 0.767 \\
\hline \multicolumn{6}{|c|}{ No. of transfusion/years } \\
\hline$<6^{\circ}$ & $66.62 \pm 12.18$ & $65.00 \pm 10.85$ & $73.26 \pm 10.97$ & $63.08 \pm 15.07$ & $67.23 \pm 9.35$ \\
\hline$\geq 6$ & $53.17 \pm 11.85$ & $57.06 \pm 11.40$ & $65.41 \pm 9.66$ & $58.47 \pm 11.54$ & $57.90 \pm 8.39$ \\
\hline$P$-value & $<0.0005$ & 0.008 & 0.003 & 0.219 & $<0.0005$ \\
\hline \multicolumn{6}{|c|}{ Ferritin $(n g / m l)$} \\
\hline$<2500$ & $60.73 \pm 13.18$ & $62.77 \pm 11.88$ & $69.53 \pm 10.84$ & $62.03 \pm 12.50$ & $63.49 \pm 9.28$ \\
\hline$\geq 2500$ & $51.12 \pm 11.08$ & $54.84 \pm 10.22$ & $64.51 \pm 9.32$ & $57.21 \pm 11.77$ & $56.25 \pm 7.88$ \\
\hline$P$-value & $<0.0005$ & 0.001 & 0.014 & 0.092 & $<0.0005$ \\
\hline \multicolumn{6}{|l|}{ Chelation } \\
\hline Yes & $52.88 \pm 11.32$ & $57.14 \pm 11.21$ & $65.49 \pm 9.39$ & $58.50 \pm 11.10$ & $57.91 \pm 7.99$ \\
\hline No & $67.13 \pm 13.32$ & $64.21 \pm 12.05$ & $72.49 \pm 12.26$ & $62.33 \pm 16.13$ & $66.70 \pm 10.97$ \\
\hline$P$-value & $<0.0005$ & 0.017 & 0.007 & 0.281 & $<0.0005$ \\
\hline \multicolumn{6}{|c|}{ Hepatitis $C$ infection } \\
\hline Yes & $50.57 \pm 11.79$ & $55.59 \pm 7.05$ & $64.71 \pm 7.39$ & $54.55 \pm 10.11$ & $55.66 \pm 6.34$ \\
\hline No & $56.62 \pm 12.99$ & $59.08 \pm 12.34$ & $67.26 \pm 10.79$ & $60.08 \pm 12.46$ & $60.38 \pm 9.57$ \\
\hline$P$-value & 0.079 & 0.117 & 0.355 & 0.168 & 0.016 \\
\hline
\end{tabular}

$76.6 \%),{ }^{16-18}$ and surprisingly even higher figures were reported in an earlier study by Abdul-Zahra et al from Southern Iraq (Basrah). ${ }^{12}$ The latter is most likely due to the fact that approximately $40 \%$ of the patients in Abdul-Zahra et al study were $2-7$ years old, unlike the current study where patients were all above the age of 6. These younger patients tend to have a better HRQoL than older children, since the complications of the disease are just emerging and major organ damage or problems related to puberty or iron overload have not yet occurred. Abdul-Zahra et al show better HRQoL scores in those $<7$ year old compared to those between 7-18 years. Moreover, and in support of the latter explanation, our study showed a significant reduction in HRQoL with age (Figure 2).

As in previous studies, the current study revealed that the 2 domains with the least scores were the physical and school functioning domains, ${ }^{11-15,18-22}$ though in some of these studies school functioning was more affected. The low physical functioning scores may be explained by multiple factors including growth retardation, chronic anemia and hypoxia causing pain and lack of energy during daily activities, this will eventually lead to missed school days due to ill health and frequent hospitalization due to various complications and the need for transfusions.

Although the current study included both child and parent proxy reports, it should be stressed that it is the child self-report that is considered the standard for measuring HRQoL, while the parent proxy assessment may serve a complementary tool, since it may give the attending physician a parent perspective of their child illness and thus better insight into the HRQoL issues that may ultimately affect the health care utilization of the respective patients. ${ }^{10,23}$ The observation of good correlation between child and parent proxy reports in the current study, has also been documented by earlier studies. ${ }^{10,23}$ Moreover, the observation that parent scores were lower than their respective children has also been observed by previous investigators. ${ }^{10,11,16,23}$ This may be due to the parent's higher degree of concern, frustration and more guarded view of their child well-being and 

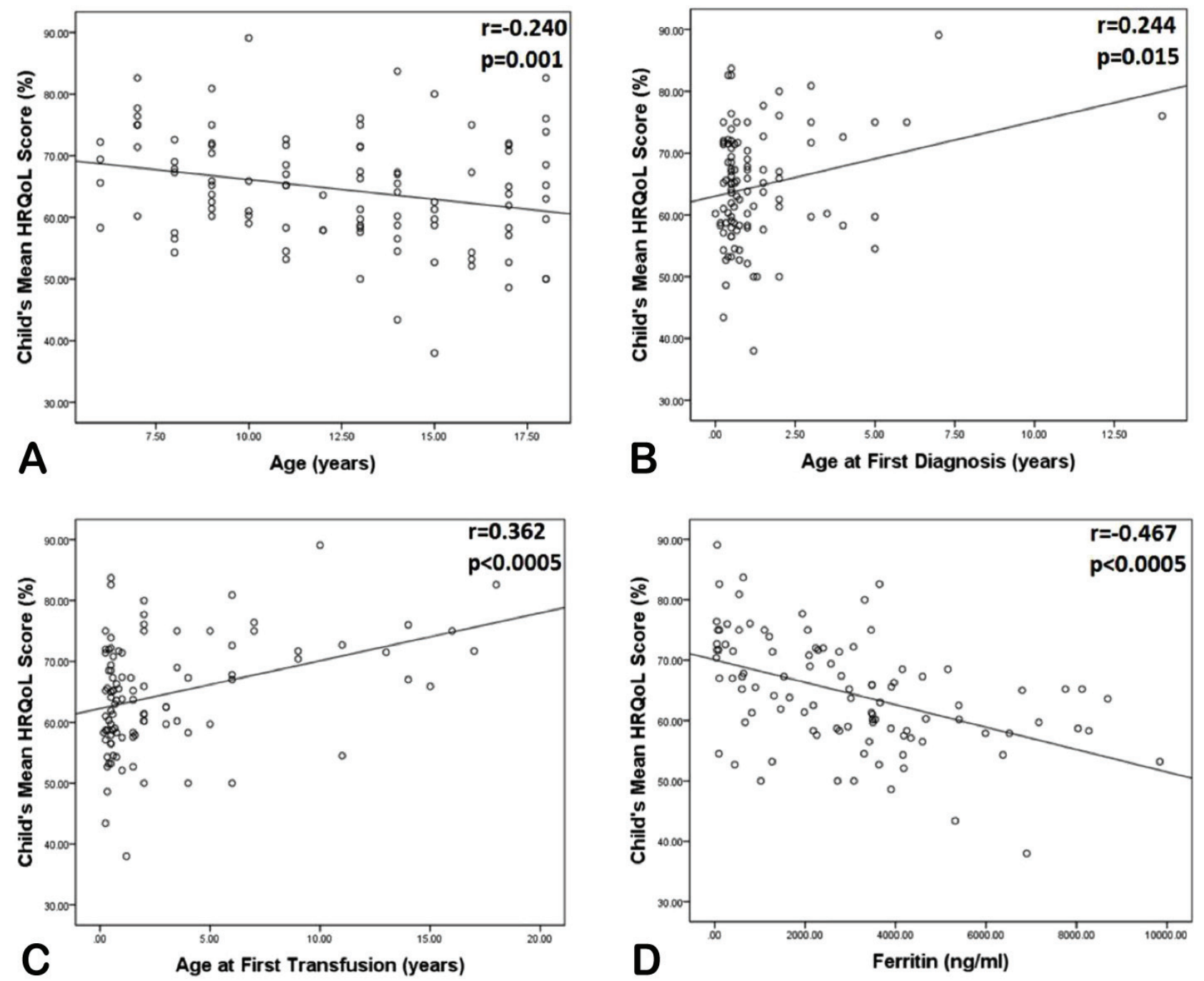

Figure 2 - Scatter plots showing the correlation between child report mean Health Related Quality of Life (HRQoL) scores with A) age, B) age at first diagnosis, $\mathrm{C}$ ) age at first transfusion, and $\mathrm{D}$ ) serum ferritin.

Table 5 - The correlations between child and parent proxy Health Related Quality of Life (HRQoL) scores and various parameters as assessed by multiple regression.

\begin{tabular}{|c|c|c|c|c|}
\hline \multirow[t]{2}{*}{ Parameter } & \multicolumn{2}{|c|}{$\begin{array}{l}\text { Child's HRQoL } \\
\text { scores }\end{array}$} & \multicolumn{2}{|c|}{$\begin{array}{l}\text { Parent proxy } \\
\text { HRQoL scores }\end{array}$} \\
\hline & $\begin{array}{c}\text { Standardized } \\
\beta\end{array}$ & $P$-value & $\begin{array}{c}\text { Standardized } \\
\beta\end{array}$ & $P$-value \\
\hline Age & -0.241 & 0.015 & -0.249 & 0.003 \\
\hline Age at first transfusion & 0.097 & 0.523 & 0.282 & 0.067 \\
\hline Age at Diagnosis & 0.091 & 0.372 & 0.038 & 0.707 \\
\hline Transfusion frequency & -0.264 & 0.050 & -0.212 & 0.117 \\
\hline S. Ferritin & -0.337 & 0.003 & -0.248 & 0.027 \\
\hline Hepatitis C infection & -0.036 & 0.711 & -0.05 & 0.604 \\
\hline Oral chelation therapy & -0.138 & 0.369 & -0.165 & 0.286 \\
\hline Mother literacy & 0.162 & 0.270 & 0.024 & 0.868 \\
\hline Father literacy & 0.132 & 0.387 & 0.037 & 0.809 \\
\hline
\end{tabular}

their tendency to be overprotective of their chronically ill child. ${ }^{23}$

An interesting observation is the significantly lower HRQoL among those with thalassemia major compared to intermedia, which is likely due to the more frequent hospital visits and transfusions, higher iron burden and its consequent complications, and higher HCV infection rates. This is consistent with at least one study on Egyptian thalassemia children. ${ }^{24}$ However, other studies, generally failed to find such a difference between the 2 phenotypes, including studies from Iran, Malaysia and Lebanon. 4,17,25,26 The Lebanese study ${ }^{4}$ even found that non-transfusion dependent thalassemia fared worse in relevance to QoL compared 
to transfusion dependent patients. However, 3 of these studies recruited adults rather than children (in contrast to our study), and their enrollees with thalassemia major were very well cared for with regular transfusion and stringent clinical monitoring, as opposed to thalassemia intermedia where transfusion and in some cases chelation were both withheld, which may increase the risk of complications, and thus lowering QoL. Musallam et al (2011), ${ }^{4}$ argued that as such, there is a need to reconsider withholding transfusions in thalassemia intermedia, if the complications are to be reduced and the QoL is to be improved.

Several factors were identified as predictors of HRQoL in the current study. Among these factors is the frequency of transfusion sessions, which negatively affected most domains as well as the mean HRQoL score. The latter observation is consistent with earlier reports from countries like Thailand and Egypt, ${ }^{23,24}$ but is contrary to other reports from countries like Oman, Pakistan, or some Middle Eastern countries, ${ }^{11,18,22}$ mainly because the former studies included like ours both major and intermedia phenotypes, while the latter focused on the major. Thalassemia major is a severe disorder with almost all patients receiving regular transfusions every 3-4 weeks, making subdivision into categories based on transfusion requirements almost redundant. Interestingly, we could not find a significant association between pre-transfusion hemoglobin and HRQoL, which is similar to studies from Northern Iran and Oman, ${ }^{22,27}$ but is contrary to others, where it was shown that higher pre-transfusion hemoglobin is associated with a better QoL. ${ }^{15,23,28}$

Another significant predictor of HRQoL was age (univariate and multivariate analysis), and the HRQoL scores would decrease with increasing age as complications and transition to adolescence and puberty takes effect. Several other investigators also documented such a reduction in QoL with increasing age, including Ismail et al ${ }^{19}$ and Dahlui et al, ${ }^{29}$ though others disputed such observation and some found that increasing age is either not associated with reduced HRQoL scores or with an increase in such scores. ${ }^{11,13,18,22,28,30}$ However, it should be noted that our study, as well as all of those outlined above, are actually cross-sectional studies, and the best way to approach this issue is through longitudinal studies, where patients are followed up throughout their disease via serial HRQoL assessments, and then a conclusive answer on this issue could be reached.

Another predictor was serum ferritin, which was linked negatively to HRQoL, as a continuous variable and also as a categorical one (with cut off $2500 \mathrm{ng} / \mathrm{ml}$ ), and remained so by multivariate analysis. This negative link to HRQoL is consistent with most studies, ${ }^{12,15,16,31}$ with some exceptions. ${ }^{22,28}$ The increased serum ferritin and thus iron overload leads to a variety of complications related to organ damage and thus expected reduction in the QoL scores. It was interesting to note that those on chelation did worse in relevance to QoL in almost all domains, than their counterparts not on chelation. The plausible explanation for the latter observation is evident from Table 1, which shows that out of the 19 patients not on chelation, 18 were thalassemia intermedia and only one was thalassemia major, and as shown in the current study thalassemia intermedia patients had a better HRQoL than their major counterparts. Moreover, those in the thalassemia intermedia subgroup and receiving chelation, are certainly more iron overloaded to warrant putting them on this therapy, and would thus be more likely to have a lower HRQoL scores. Caocci et al ${ }^{11}$ in their study on Middle Eastern thalassemic patients, reported that delayed start of chelation is linked to poor HRQoL, an observation which we could not confirm as significant in the current study. It is important to note that with the provision of deferasirox freely by the health authorities to patients with hemoglobinopathies, this oral chelating agent almost replaced the more cumbersome subcutaneous chelator "deferoxamine" for routine use in most centers throughout our country. All enrolled patients on chelation were receiving deferasirox, and none were on subcutaneous deferoxamine at the time of enrollment; the latter drug has been associated with lower HRQoL by some studies. ${ }^{23,28}$

The current study also focused on the educational status of the parents, and it was documented that parents' literacy is associated with higher HRQoL scores, an observation which is not unexpected and has been documented by others. ${ }^{12}$

In conclusion, it was observed that Iraqi Kurd children and adolescents with thalassemia have a reduced HRQoL, affecting all domains whether physical, or psychosocial. The need to implement programs that target the patients' perceived issues relevant to their disease, including psychosocial support to improve the patient self-image and self-esteem, and facilitating normal life style. Moreover, educational programs which take in consideration the education backgrounds of the parents, and centered on handling various complications promptly, safe transfusion practices, and ensuring the regular and correct use of chelators would be instrumental. It would also be worthwhile to create management programs that are more patient centered rather than health provider centered, namely, 
providing transfusions or assessment appointments on weekends to limit lost school time. Furthermore, certain categories of patients like those receiving more frequent transfusions, have high serum ferritin, or have active hepatitis $C$ need more attention and care to improve their HRQoL by appropriate targeted managements.

\section{References}

1. Kelly N. Thalassemia. Pediatr Rev 2012; 33: 434-435.

2. Salah NB, Bou-Fakhredin R, Mellouli F, Taher AT. Revisiting Beta Thalassemia Intermedia: Past, present, and future prospects. Hematology 2017; 22: 607-616

3. Piel FB, Weatherall DJ. The $\alpha$-Thalassemias. $N$ Engl J Med 2014; 371: 1908-1916.

4. Musallam KM, Khoury B, Abi-Habib R, Bazzi L, Succar J, Halawi R, Hankir A, Koussa S, Taher AT. Health-related quality of life in adults with transfusion-independent thalassemia intermedia compared to regularly transfused thalassemia major: new insights. Eur J Haematol 2011; 87: 73-79.

5. Marcel WM. Definitions of quality of life: What has happened and how to move on. Top Spinal Cord Inj Rehabil 2014; 20: 167-180

6. Petersson C, Huus K, Åkesson K, Enskär K. Children's experience about structured assessment of health-related quality of life during a patient encounter. Child: Health Care and Development 2016; 42: 424-432.

7. Varni JW, Seid M, Kurtin PS. PedsQL 4.0: reliability and validity of the pediatric quality of life inventory version 4.0 generic core scales in healthy and patient populations. Med Care 2001; 39: 800-812.

8. Varni JW, Seid M, Knight TS, Uzark K, Szer IS. The PedsQL 4.0 generic core scales: sensitivity, responsiveness, and impact on clinical decision making. J Behav Med 2002; 25: 175-193.

9. Varni JW, Burwinkle TM, Seid M. The PedsQL 4.0 as a school population measure: feasibility, reliability, and validity. Qual Life Res 2006; 15: 203-215.

10. Varni JW, Limbers CA, Burwinkle TM. How young can children reliably and validly self-report their health-related quality of life?: An analysis of 8,591 children across age subgroups with the PedsQL ${ }^{\mathrm{TM}} 4.0$ Generic Core Scales. Health Qual Life Outcomes 2007; 5: 1.

11. Caocci G, Efficace F, Ciotti F, Roncarolo MG, Vacca A, Piras E, et al. Health related quality of life in Middle Eastern children with beta-thalassemia. BMC Blood Disord 2012; $12: 6$.

12. Abdul-Zahra HA, Hassan MK, Ahmed BA. Health-related quality of life in children and adolescents with $\beta$-thalassemia major on different Iron chelators in Basra, Iraq. J Pediatr Hematol Oncol 2016; 38: 503-511.

13. Gharaibeh HF, Gharaibeh MK. Factors influencing health related quality of life of thalassaemic Jordanian children. Child Care Health Dev 2011; 38: 211-218.

14. Ayoub MD, Radi SA, Azab AM, Abulaban AA, Balkhoyor AH, Bedair SW, Aljaouni SK, Kari JA. Quality of life among children with beta-thalassemia major treated in Western Saudi Arabia. Saudi Med J 2013; 34: 1281-1286.
15. Elalfy MS, Farid MN, Labib JH, RezkAllah HK. Quality of life of Egyptian $\beta$-thalassemia major children and adolescents. Egyptian J Haematology 2014; 39: 222-226.

16. Boonchooduang N, Louthrenoo O, Choeyprasert W, Charoenkwan P. Health-related quality of life in adolescents with thalassemia. Pediatr Hematol Oncol 2015; 32: 341-348.

17. Ismail M, Chun CC, Yousaf NAM, Shahar S, Munaf ZA, Rajikan R, Quality of Life among thalassaemia children, adolescent and their caregivers. Sains Malaysiana 2013; 42: 373-380.

18. Sultana R, Humayun S, Noor T, Humayun S, Zafar U. Impact of thalassaemia on quality of Life. J Soc Obstet Gynaecol Pak 2016; 6: 156-160.

19. Ismail A, Campbell MJ, Ibrahim HM, Jones GL. Health related quality of life in Malaysian children with thalassemia. Health Qual Life Outcomes 2006; 4: 39.

20. Devarshi S, James S, Najafzadeh E, Pawar S, Kalrao V, Bafna $\mathrm{V}$. Assessment of quality of life, complications and posttransfusion adverse reactions in thalassemia pediatric in Tertiary Care Hospital. Int J Pharm Pharm Sci 2016; 8: 317-323.

21. Wahyuni MS, Ali M, Rosdiana N, Lubis B. Quality of life assessment of children with thalassemia. Paediatr Indones 2011; 51: 163-169.

22. Mevada ST, Al Saadoon M, Zachariah M, Al Rawas AH, Wali Y. Impact of burden of thalassemia major on health-related quality of life in Omani children. J Pediatr Hematol Oncol 2016; 38: 384-388.

23. Surapolchai P, Satayasai W, Sinlapamongkolkul P, Udomsubpayakul U. Biopsychosocial predictors of health related quality of life in children with thalassemia in Thammasat University Hospital. J Med Assoc Thai 2010; 93 Suppl 7: S65-S75.

24. Adam S, Afifi H, Thomas M, Magdy P, El-Kamah G. Quality of life outcomes in a Pediatric thalassemia population in Egypt. Hemoglobin 2017; 41: 16-20.

25. Haghpanah S, Vahdati S, Karimi M. Comparison of the quality of life in patients with $\beta$-thalassemia intermedia and $\beta$-thalassemia major in Southern Iran. Hemoglobin 2017; 41: 169-174

26. Gan GG, Hue YL, Sathan J. Factors affecting quality of life in adult patients with thalassemia major and intermedia. Ann Acad Med 2016; 45: 520-523.

27. Jafari-Shakib A, Davoudi-Kiakalaye A, Pour-Fathollah AA, Jafari-Shakib R, Mohtasham-Amiri Z. Health-related quality of life in $\beta$-thalassemia major children in North of Iran. IJBC 2016; 8: 108-111.

28. Thavorncharoensap M, Torcharus K, Nuchprayoon I, Riewpaiboon A, Indaratna K, Ubol BO. Factors affecting health-related quality of life in Thai children with thalassemia. BMC Blood Disord 2010; 10: 1.

29. Dahlui M, Hishamshah MI, Rahman AJ, Aljunid SM. Quality of life in transfusion-dependent thalassaemia patients on desferrioxamine treatment. Singapore Med J 2009; 50: 794-799.

30. Tefler P, Constantinidou G, Andreou P, Christou S, Modell B, Angastiniotis M. Quality of Life in thalassaemia. Ann NY Acad Sci 2005; 1054: 273-282.

31. Tuysuz G, Tayfun F. Health-related quality of life and its Predictors among transfusion-dependent thalassemia patients. J Pediatr Hematol Oncol 2017; 39: 332-336. 